\title{
Dengue infection in the nervous system
}

\author{
Infecção por dengue no sistema nervoso
}

Dear Editor,

The recent publication on "dengue infection in the nervous system” is very interesting ${ }^{1}$. Puccioni-Sohler et al. noted that the "absence of reliable laboratory tests aiming at early and accurate diagnosis of infection in the nervous system is significant" and "the analysis of clinical characteristics and CSF fluid of patients displaying neurological manifestations related to arboviruses is crucial, in order to determine the development of the disease mechanisms and improve diagnostic methods of infection within each virus group ${ }^{1}$." We agree with PuccioniSohler et al. that the neurological complications due to dengue are an important problem in medical practice. We would like to add to the discussion on the problem of diagnosis. Firstly, the neurological presentation in dengue usually occurs late in the course of infection. The early diagnosis of dengue might not correlate with the early diagnosis of neurological complication. In addition, the diagnosis of dengue in an endemic area usually relies on the clinical diagnosis, and the role of immunological or molecular diagnosis is extremely limited and considered not cost effective. In addition, the CSF examination is rarely done in patients with dengue due to the problem of thrombocytopenia. In patients where a CSF examination is done, based on previous reports from highly endemic areas of dengue, the detection rate of dengue is very low ${ }^{2}$. Nevertheless, we agree that the accurate diagnosis of dengue neuropathy is needed. At least, it can be useful epidemiological data.

Sora Yasri ${ }^{1}$, Viroj Wiwanitkit ${ }^{2}$

\section{References}

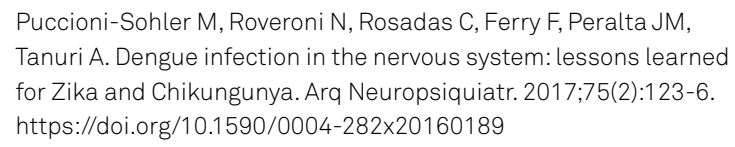

Puccioni-Sohler M, Roveroni N, Rosadas C, Ferry F, Peralta JM, Tanuri A. Dengue infection in the nervous system: lessons learned for Zika and Chikungunya. Arq Neuropsiquiatr. 2017;75(2):123-6. https://doi.org/10.1590/0004-282×20160189

2. Olsen SJ, Campbell AP, Supawat K, Liamsuwan S, Chotpitayasunondh T, Laptikulthum $S$ et al.Infectious causes of encephalitis and meningoencephalitis in Thailand, 2003-2005. Emerg Infect Dis. 2015;21(2):280-9. https://doi.org/10.3201/eid2102.140291

${ }^{1}$ KMT Primary Care Center, Bangkok Thailand;

${ }^{2} V$ Visiting professor, Hainan Medical University, China.

Correspondence: Sora Yasri; KMT Primary Care Center, Bangkok Thailand; Email: beuyjoob@hotmail.com

Conflict of interest: There is no conflict of interest to declare.

Received 24 February 2017; Accepted 21 March 2017. 